\title{
Temporal Triangular Alopesili İki Olgu
}

\section{Two Cases of Temporal Triangular Alopecia}

\section{Hilal Semra HANCER}

Denizli Devlet Hastanesi, Deri ve Zührevi Hastalıkları Kliniği, Denizl

\begin{abstract}
$\overline{\mathbf{O z}}$
Temporal triangular alopesi (TTA), doğumda ya da erken çocukluk çağında ortaya çıkan, sıklıkla frontotemporal bölgede unilateral ya da bilateral yerleşim gösteren, asemptomatik, skar bırakmayan lokalize saç kaybıdır. Etkilenen bölgede tam bir saç kaybı olabilir ya da ince vellüs tüyleri görülebilir. Alopesi genellikle kalıcıdır. Çoğunlukla alopesi areata ile karıștırılmasından dolayı literatürde bildirilen TTA olguları az sayıdadır. Burada öykü ve klinik inceleme ile TTA tanısı alan iki olgu sunularak literatür gözden geçirilecektir.
\end{abstract}

Anahtar Kelimeler: Alopesi, Konjenital Triangular Alopesi, Temporal Triangular Alopesi

\section{Giriş}

Konjenital triangular alopesi ve Brauer nevüs gibi isimlerle de adlandirılan temporal triangular alopesi (TTA), ilk kez 1905 yilında Saboraud tarafından tanımlanmıştır. Klinik olarak frontotemporal bölgeye yerleșen oval, üçgen ya da lanset şeklindeki skar bırakmayan alopesik yamalar ile karakterizedir (1).

TTA etyopatogenezi tam olarak bilinmemekle birlikte sporadik olarak meydana geldiği düşünülmektedir. Literatürde paradominant geçiş olabileceği öne sürülen ailesel olgular ile sendromlarla beraber görülebilen otozomal dominant geçişli olgular da bildirilmiştir (2).

Lezyonların asemptomatik olması ve alopesi areata, trikotillomani, tinea kapitis, traksiyonel alopesi gibi saç hastalıklarıyla karışabilmesi sebebiyle literatürde bildirilen TTA sayısı azdır (3). Gereksiz tedavilerin önlenmesi açısından TTA'nin tanınması önem taşır.

Burada klinik ve dermatoskopik inceleme sonucu TTA tanısı alan iki olgu sunularak literatür gözden geçirilecektir.

\section{Olgu 1}

Sekiz yaşındaki erkek çocuk alın yan tarafında bulunan lokalize saç kaybı sebebiyle polikliniğe başvurdu. Lezyonun üç yaş civarında oluştuğu öğrenildi. Hastanın özgeçmişinde herhangi bir

\begin{tabular}{ll}
\hline Hilal Semra HANÇER & ORCID No \\
0000-0002-1570-2553
\end{tabular}

Başvuru Tarihi / Received: 09.07.2019

Kabul Tarihi / Accepted : $\quad 23.10 .2019$

Adres / Correspondence : Hilal Semra HANÇER

Denizli Devlet Hastanesi, Deri ve Zührevi Hastalıkları Kliniği, 20100, Denizli

e-posta / e-mail hilalscelebi@gmail.com

\begin{abstract}
Temporal triangular alopecia (TTA) is an asymptomatic, nonscarring localized hair loss that occurs in birth or early childhood, often unilateral or bilateral in the frontotemporal region. The affected area may have a complete hair loss or thin vellus hairs. Alopecia is usually permanent. There are few cases of TTA reported in the literature because the majority of cases of TTA are misdiagnosed as alopecia areata. Here, two cases with TTA diagnosed by history and clinical examination will be presented and the literature will be reviewed.
\end{abstract}

Keywords: Alopecia, Congenital Triangular Alopecia, Temporal Triangular Alopecia

hastalığı yoktu. Anne-baba arasında akrabalık yoktu. Anne ve babada bilinen bir saç hastalı̆̆ bulunmuyordu. Fakat hastanın iki yaş büyük erkek kardeşinde de benzer saç kaybının bulunduğu öğrenildi.

Diğer yönlerden sağlıklı olan hastanın dermatolojik muayenesinde sağ frontotemporal bölgeye sınırlı $3 \times 2 \mathrm{~cm}$ çapında, oval alopesik yama olduğu görüldü (Resim 1). Lezyon üzerinde skuam, eritem, atrofi, skar dokusuna rastlanılmadi. Yapılan çekme testi normal sınırlar içindeydi. Dermatoskop ile yapılan incelemede, terminal kıllarla çevrili ince vellus kıllar saptandi; herhangi kutanöz değişiklik görülmedi. Laboratuar tetkiklerinde hemogram, tiroid fonksiyon testleri, ferritin, B12, folat, D vitamininin normal sınırlar içinde olduğu görüldü. Hastanın erkek kardeşi daha sonraki poliklinik ziyaretinde muayene edildi. Sağ frontotemporal bölgede yaklaş1k $3.5 \times 2 \mathrm{~cm}$ boyutunda ince vellus k1llar bulunan alopesik alan izlendi. Yapilan incelemeler sonucunda her iki kardeşte de temporal triangular alopesi bulunduğu saptandı.

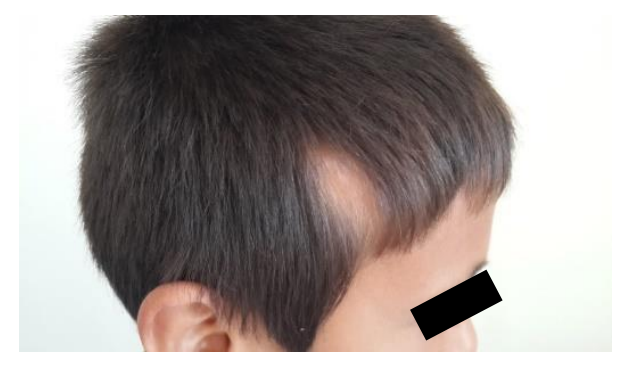

Resim 1. Sağ frontotemporal bölgedeki lanset şeklinde alopesik alan

Olgu 2

Üç yaşındaki erkek hasta, yaklaşık bir yıl önce meydana gelen lokalize saç kaybı ile polikliniğe 
başvurdu. Hastanın özgeçmişinde ve soygeçmişinde herhangi bir özellik yoktu.

Dermatolojik muayenede sol frontotemporal bölgede $2 \times 2.5 \mathrm{~cm}$ çapında, üzerinde eritem, skuam, atrofi gibi kutanöz değişikliklerin olmadığı alopesik yama görüldü (Resim 2). Dermatoskopik incelemede terminal kıllarla çevrili ince vellus kıllar saptandı. Yapılan laboratuar tetkiklerinde hemogram, tiroid fonksiyon testleri, ferritin, B12, folat ve $\mathrm{D}$ vitamini düzeyleri normal sınırlar içerisindeydi. Hastaya temporal triangular alopesi tanıs1 koyularak aileye bilgi verildi. Topikal minoksidil \%2 sprey önerilerek iki ay sonra kontrole çağrıldı.

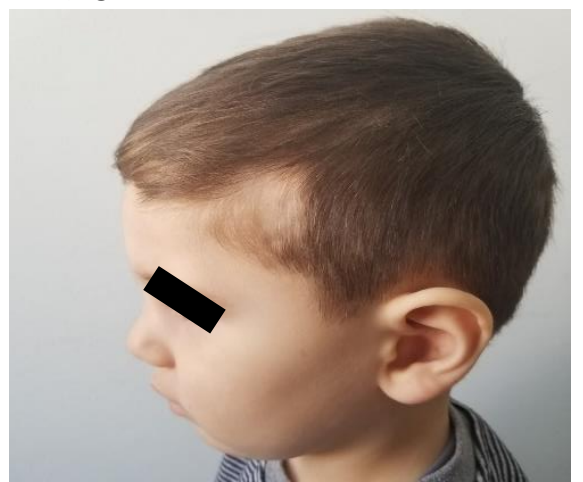

Resim 2. Sol frontotemporal bölgede üçgen şeklinde alopesik alan

\section{Tartışma}

TTA, genellikle frontotemporal bölgeye sinırlı, terminal kılların yerini vellus kıllarının aldığı skar bırakmayan, stabil seyreden bir alopesi türüdür (2). Her iki cinsiyet eşit olarak etkilenir. Çoğunlukla iki ile dokuz yaş arasındaki çocuklarda görülmekle birlikte doğumdan itibaren görülen vakalar ile erişkinlik döneminde ortaya çıkan olgular bildirilmiştir $(1,4)$.

TTA’nın oluşma sıklığının \%0.11 olduğu tahmin edilmektedir (4). Şimdiye kadar bildirilen 130 olgu bulunmaktadır (5). Her iki cinsiyette eşit oranda görülmektedir (6). Lezyonlar çoğunlukla unilateral yerleşimli olup, bilateral tutuluma daha az siklıkta rastlanmaktadır. Yamazaki ve arkadaşlarının yaptığı bir çalışmada olguların $\% 55.8$ 'inde sol frontotemporal bölge tutulmuş iken, $\% 30.8$ 'inde sağ taraf etkilenmiş, \%13.5'unda ise bilateral tutulum saptanmıştır (4). Bizim olgumuzun birinde sağ taraf diğerinde sol taraflı tutulum görüldü.

TTA, sıklıkla sporadik olarak ortaya çıkar. Literatürde fakomatozis pigmentovaskülaris, Down sendromu, Dandy-Walker malformasyonu, mental retardasyon, epilepsi, kalp hastalıkları, kemik ve diş anormallikleriyle birliktelik gösteren olgular bildirilmiştir (2). Biri baba-kız ikisi anne-kız olmak üzere şimdiye kadar üç ailesel olgu bildirilmiştir (4). Ailesel olgularda paradominant geçişin rol oynayabileceği düşünülmektedir (7). Birinci olgumuzda her iki erkek kardeşte TTA bulunduğu görüldü. Literatürde kardeş olan TTA olgularına rastlanmamıştır, bu bilgi TTA'nın genetik geçişinin değerlendirilmesinde faydalı olabilir.

Histopatolojide epidermis ve dermiste değişiklik görülmez. Skalpte bulunan toplam folikül sayısı normaldir; fakat folikül boyutları normalden küçüktür. Foliküllerin çoğunluğunda da vellüs kıllar ile intermediate k1llar bulunur, terminal k1llar saptanmaz (5).

İnvaziv işlem olmaması ve kolay ulaşılabilir olması sebebiyle dermatoskopi TTA için önemli bir tanı aracıdır. Dermatoskopide TTA'da terminal kıllarla çevrili deride ince, beyaz kıllar, kıllar arasında çap farklılıkları, boş foliküller ve beyaz noktalar görülür (6). Inui ve arkadaşları tarafindan klinik ve dermatoskopik özellikler belirlenerek TTA için dört maddelik tanı kriterleri oluşturulmuştur: (I) skalpte frontotemporal bölgeyi çevreleyen üçgen veya lanset şeklinde alopesik yama, (II) terminal kılların çevrelediği normal folikül ağzından çıkan vellüs kıllar, (III) kırık veya ünlem işareti kıllar ile siyah ve sarı noktaların olmaması, (IV) altı aylık takipte saç uzamasının gerçekleşmemesi (3). Bizim olgularımızdaki frontotemporal bölgeye sinırlı alopesik yamaların dermatoskopik incelemesinde, normal foliküler açıklıklar ile lezyon ortasında ince vellüs kıllar görüldü. Lezyonlar, periferinde terminal killar ile çevriliydi; sarı/siyah noktalar, ünlem işareti bulgusu, folikül kayıpları, skuam, vasküler değişiklikler saptanmadi.

Alopesi areata (AA) ile karıştırılması sebebiyle literatürdeki TTA'lı olguların sayısının az olduğu düşünülmektedir. TTA'de lezyonlar erken çocukluk döneminde oluşur ya da konjenital olarak bulurken AA herhangi bir yaşta olabilir. TTA, frontotemporal, temporal nadiren de oksipital bölgeyi tutarken, AA her bölgeyi tutabilir. TTA dermatoskop ile incelendiğinde periferde terminal kıllar, merkezde normal foliküler açıklık ve ince vellüs kıllar olan yama görülürken; AA'da sarı ve siyah noktalar, ünlem işareti bulgusu, distrofik k1llar görülür (5).

Traksiyonel alopesi, trikotillomani, tinea kapitis, nevüs sebaseus TTA'nın diğer ayırıcı tanıları arasında değerlendirilebilir.

TTA, benign seyirli bir saç hastalı̆̆ıdır. Özellikle AA ve tinea kapitis ile ayrımının iyi yapılıp gereksiz tedavilerden kaçınılması önemlidir. TTA'nın etkili bir tedavisi bulunmamaktadır. Topikal minoksidil ile tedavi edilen olgular bulunmaktadır (8). Lezyon küçük ve lokalizeyse seçilmiş vakalarda cerrahi rezeksiyon yapilabilir (1). Bilateral TTA'sı olan bir olguda foliküler ünite transplantasyonu yapılmış, ve altı yıllık takipte saçlarda dökülme izlenmemiştir (9). Özellikle kozmetik kaygısı yüksek olan hastalara saç transplantasyonu önerilebilir. Her iki olgumuzda da aileye lezyonun benign karakterde olduğu anlatıldı. 
İkinci olguya topikal minoksidil başlanarak kontrole çağrıldı.

Hasta Onamı: Birinci olgunun ailesinden hasta onamı 14.01.2019 tarihinde, ikinci olgunun ailesinden hasta onamı 28.02.2019 tarihinde alınmıştır.

\section{Kaynaklar}

1. Viswanath V, Kalambe V, Sanap D. Congenital triangular alopecia: Clinical and dermoscopic differentials. Indian J Paediatr Dermatol. 2019;20(1):75-7.

2. Campos JG, Oliveira CM, Romero SA, Klein AP, Akel $\mathrm{PB}$, Pinto GM. Use of dermoscopy in the diagnosis of temporal triangular alopecia. An. Bras. Dermatol. 2015;90(1):123-5

3. Inui S, Nakajima T, Itami S. Temporal triangular alopecia: trichoscopic diagnosis.J Dermatol. 2012;39:572-4.
4. Yamazaki M, Irisawa R, Tsuboi R. Temporal triangular alopecia and review of 52 past cases. J Dermatol. 2010;37(4):360-2.

5. Diniz TACB, Abuawad YG, Silva FO, et al. Triangular temporal alopecia - two case reports, dermoscopy and review. J Dermat Cosmetol. 2018;2(1):34-6.

6. Fernández-Crehuet P, Vaño-Galván S, Martorell-Calatayud A, et al. Clinical and trichoscopic characteristics of temporal triangular alopecia: A multicenter study. J Am Acad Dermatol. 2016;75(3):634-7.

7. Happle R.Congenital triangular alopecia may be categorized as a paradominant trait. Eur J Dermatol. 2003;13(4):346-7.

8. Bang CY, Byun JW, Kang MJ, et al. Successful Treatment of Temporal Triangular Alopecia with Topical Minoxidil. Ann Dermatol. 2013;25(3):387-8.

9. Unger R, Alsufyani MA. Bilateral Temporal Triangular Alopecia Associated with Phakomatosis Pigmentovascularis Type IV Successfully Treated with Follicular Unit Transplantation. Case Rep Dermatol Med. 2011;2011:129541. 